\title{
The Effect of Vitamin C on Lead-induced Plasma BiochemicalAlterations in Fish, Cyprinus carpio
}

\author{
Kimiya Nourian 1 (D), Hassan Baghshani ${ }^{* 2}$ id , Davar Shahsavani 3 (i) \\ 1. Graduate DVM Student, Faculty of Veterinary Medicine, Ferdowsi University of Mashhad. Mashhad, Iran. \\ 2. Department of Basic Sciences, Faculty of Veterinary Medicine, Ferdowsi University of Mashhad. Mashhad, Iran. \\ 3. Department of Food Hygiene and Aquaculture, Faculty of Veterinary Medicine, Ferdowsi University of Mashhad. Mashhad, Iran.
}

\begin{tabular}{ll}
\hline Article Info & A B S T R A C T \\
\hline $\begin{array}{l}\text { Article type: } \\
\text { Original Article }\end{array}$ & Background: \\
\hline Article History: & This study was conducted to investigate whether vitamin C can protect \\
Received: $2019-03-03$ & against plasma biochemical changes induced by lead poisoning in Cyprinus \\
Accepted: $2019-04-17$ & carpio.
\end{tabular}

Accepted: 2019-04-17

\author{
* Corresponding author: \\ Hassan Baghshani \\ Department of Basic Sciences, \\ Faculty of Veterinary Medicine, \\ Ferdowsi University of Mashhad. \\ Mashhad, Iran. \\ E-mail: \\ baghishani@ferdowsi.um.ac.ir
}

\section{Methods:}

Three groups of common carp (n=30/group) were used in this study. Group 1 served as control, Group 2 was exposed to lead acetate (5 mg/L) for 15 days, and Group 3 received vitamin C (500 $\mathrm{mg} / \mathrm{kg})$ during the same duration of lead exposure.

\section{Results:}

The blood lead concentrations in Groups 2 and 3 showed a significant rise as compared to that in the control group $(\mathrm{p}<0.05)$. Also, the plasma malondialdehyde (MDA) concentration increased considerably following in groups exposed to lead acetate, compared to that in controls. Vitamin C supplementation decreased the rise in plasma MDA insignificantly, compared that in Group 2. The plasma values of creatinine and alanine aminotransferase (ALT) increased in Group 2 compared to that in controls. Also, vitamin C treatment significantly decreased plasma ALT and creatinine concentrations, compared to those in Group 2. Values of other plasma parameters including aspartate aminotransferase, alkaline phosphatase, lactate dehydrogenase, gammaglutamyl transferase, albumin, glucose, total protein, cholesterol, urea, uric acid and triglyceride showed no significant alterations among the treatment groups.

\section{Conclusion:}

The results suggest that vitamin $\mathrm{C}$ have some beneficial effects against lead toxicity in common carp. However, elucidation of the precise mechanism of the protective effects of vitamin $\mathrm{C}$ against lead toxicity warrants further investigations.

Keywords:

Cyprinus Carpio; Lead Toxicity; Liver Enzymes; Plasma Malondialdehyde; Vitamin C.

How to cite this paper

Nourian K, Baghshani H, Shahsavani D. The Effect of Vitamin C on Lead-induced Plasma BiochemicalAlterations in Fish, Cyprinus carpio. Iran J Toxicol. 2019; (2):25-29

\section{INTRODUCTION}

The utilization of heavy metals in many industries has contaminated fresh waters. Since heavy metals are not essential for living creatures, these toxic substances pose health risks to aquatic environments and humans, which outweigh their benefits. Due to its physicochemical properties, lead is widely used in paints, printing materials, refinery processes, smelting, batteries and fertilizers. Nowadays, lead is also traced in many aquatic ecosystems $(\underline{1,2})$.
The adverse effect of heavy metals in fish and humans, which are established by many studies, has raised the public awareness about the safety of water resources being at risk due to contaminations. Fish can accumulate lead in their organs, thus they serve as practical indicators of toxic metals contamination affecting the aquatic environment. The main concern is that the heavy metals accumulated in fish will eventually end up in human food chains ( $\underline{3})$. 
Numerous human health conditions are associated with heavy metals poisoning, depending on the level of exposure. Lead toxicity can cause headaches, convulsion, weight loss, allergies, intellectual impairment, muscle weakness, and certain CNS conditions, such as peripheral neuropathies ( $\underline{1}$ ). Further, the toxicity can cause nephropathy, renal failure, reproductive and gastrointestinal disorders, and hematologic dysfunctions, which may lead to coma or death $(\underline{1,4})$.

With respect to the cellular mechanisms of the adverse effects, heavy metals toxicity is known to cause the release of reactive oxygen species (ROS), which depletes the affected cells of their antioxidant reservoirs and prevents the detoxifying enzymes from eliminating ROS $(\underline{1,2})$. Toxic metals can also impair biological functions in lipids; proteins and even DNA (4). Vitamin C is known to be a free radical scavenger, which support the elimination of ROS from cells ( 1 ). The therapeutic effects of vitamin $C$ in lead poisoning cases have been demonstrated in humans, animals and various aquatic species $(\underline{1,5-7})$. At the molecular level, the therapeutic effects of vitamin $C$ in lead toxicity may also be linked to the inhibition of the lead absorption from the intestinal tract ( $\underline{4}$ ) and its affinity to bind this heavy metal (ㅁ).

Cyprinus carpio (C. carpio) is a popular freshwater fish and one of the world's most widely consumed aquatic species. The aim of this study was to investigate the role of vitamin $\mathrm{C}$ to induce protective enzymatic modifications following experimental lead poisoning in C. carpio.

\section{MATERIALS AND METHODS}

Chemicals: The supplier of the vitamin $C$ utilized in this study was Chemifarma Co. (Tehran, Iran). 2,4Dinitrophenylhydrazine (DNPH) and 2-thiobarbituric acid (TBA) were produced by Sigma Chemical Co. (St. Louis, MO, USA). The rest of the chemicals used in this study were of analytical grade, supplied by Sigma (St. Louis, MO, USA) or Merck (Darmstadt, Germany). Other kits were commercially available from Pars Azmoon (Tehran, Iran) and were utilized for the enzymatic assays.

Experimental Design and Sampling: The Research Ethics Committee of the Faculty of Veterinary Medicine, Ferdowsi University approved the study protocol. Healthy common carp $(\mathrm{N}=90)$ weighing $100 \pm 10 \mathrm{~g}$ were randomly and equally divided in three groups ( $N=30 /$ group). Two weeks before the onset of the study, the fish were transferred to aquaria to get acclimatized and were fed daily with commercial fish diet ( $2 \%$ body weight). Each group were held separately in 250 liter capacity, glass aquarium tanks at $24-26^{\circ} \mathrm{C}$ temperature, exposed to a photoperiod of 12:12hr light-dark cycle. The aquarium water was refreshed daily and the dissolved oxygen content and $\mathrm{pH}$ were kept at 5.5-6 ppm and 7.4, respectively. The controls (Group 1) were kept in normal fresh water throughout the study (15 days). The fish in Group 2 were kept in water containing $5 \mathrm{mg} / \mathrm{L}$ lead acetate, and the fish in Group 3 received vitamin C (500 mg/kg) while being exposed to lead acetate $(5 \mathrm{mg} / \mathrm{L})$ dissolved in the aquarium water. At the completion of the experiments (15 days), blood samples were taken from 10 fish in each group, using heparinized tubes under MS-222 anesthesia. Plasma samples were prepared by centrifugation at $750 \mathrm{G}$ for $20 \mathrm{~min}$, and stored at $-70^{\circ} \mathrm{C}$ prior to further analyses (ㅁ).

Biochemical Assays: Sample preparation was done as described previously to measure blood lead levels (ㅁ). Lead concentrations in the blood samples were determined, using an atomic absorption spectrophotometer (Perkin-Elmer 3030) at $283.3 \mathrm{~nm}$ wavelength. The limit of detection for the analyses was $5 \mathrm{ng} / \mathrm{g}$ and the recovery for spiked samples was $>\% 90$. The circulating values of lactate dehydrogenase (LDH), alkaline phosphatase (ALP), alanine aminotransferase (ALT), gamma-glutamyl transferase (GGT), aspartate aminotransferase (AST), albumin, glucose, triglyceride, total protein, cholesterol, creatinine, urea, and uric acid were measured in plasma, applying diagnostic colorimetric kits (Pars Azmoon. Tehran, Iran). The malondialdehyde (MDA) quantity was determined based on the absorbance changes at $539 \mathrm{~nm}$ which is caused by its reaction with 2-thiobarbituric acid $(\underline{9,10})$ using $156,000 / \mathrm{M} / \mathrm{cm}$ as the extinction coefficient.

Statistical Analyses: The data were statistically analyzed using one-way analysis of variance followed by Bonferroni multiple range test. All data are presented as the mean \pm standard error (SE) in various tables, with the significance level set at $\mathrm{P}<0.05$.

\section{RESULTS}

No mortality was observed in any of the fish throughout the study. Lead exposure caused significant rise in the blood lead and MDA levels of fish in Group 2 compared to those in the controls $(\mathrm{p}<0.05)$. Vitamin $C$ treatment decreased the values for the blood lead and MDA concentrations insignificantly in Group 3 as compared to those in the lead-exposed Group 2 (Figures 1 and 2). The plasma biochemical indices are shown in Figures 3 to 7 . Based on the results, the creatinine and ALT concentrations significantly increased following lead exposure compared to those in the controls. Vitamin C administration in Group 3 decreased the levels of plasma creatinine and ALT compared to those in Group 2, the amounts of which being comparable to those documented in the controls (Figures 4 and 5).

The values of other plasma indices including aspartate aminotransferase (AST), alkaline phosphatase (ALP), lactate dehydrogenase (LDH), gammaglutamyl transferase (GGT), urea, uric acid (Figures 3-5), albumin, glucose, total protein, cholesterol and triglyceride (Figures 6 and 7) indicated no significant alterations in Groups 2 and 3. 


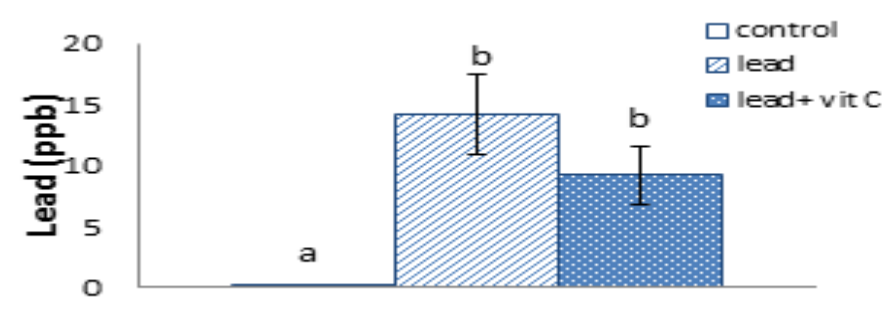

Figure 1. Blood lead concentrations $(\mu \mathrm{g} / \mathrm{L})$ in experimental groups. Data are mean \pm SEM ( $n=10$ /group).

a,b Values with no common superscript differ significantly $(\mathrm{P}<0.05)$.

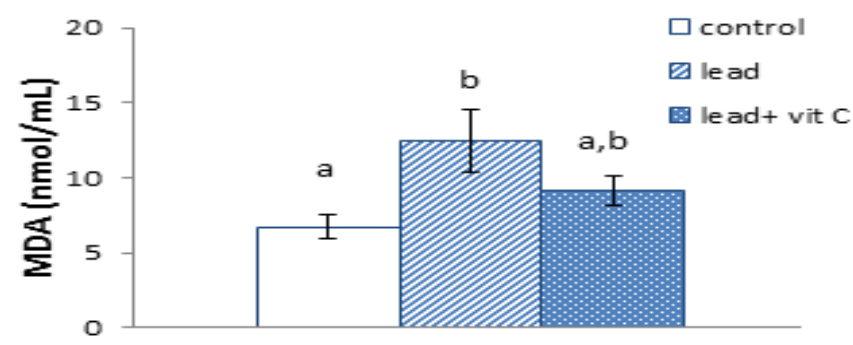

Figure 2. Plasma levels of MDA $(\mathrm{nmol} / \mathrm{mL})$ in experimental groups. Data are mean \pm SEM ( $n=10$ /group).

a,b Values with no common superscript differ significantly $(\mathrm{P}<0.05)$.

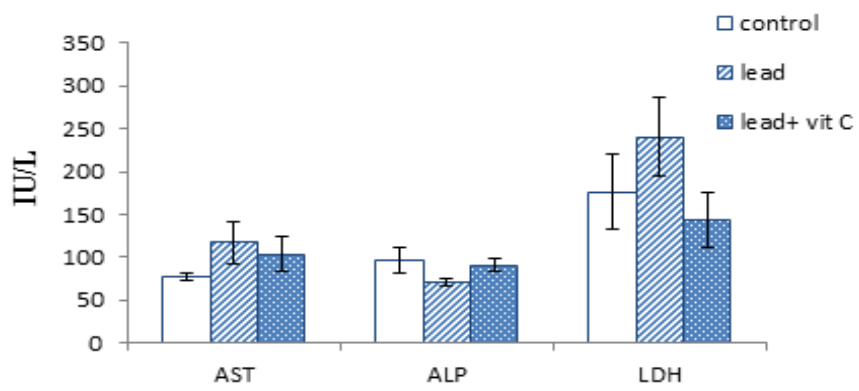

Figure 3. Plasma levels of AST, ALP and LDH (IU/L) in experimental groups ( $\mathrm{n}=10 /$ group).

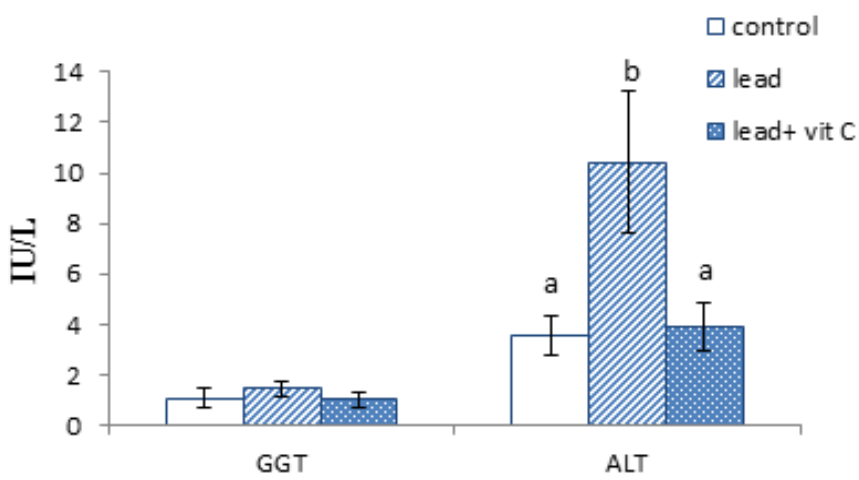

Figure 4. Plasma levels of GGT and ALT (IU/ L) in experimental groups. Data are mean \pm SEM ( $n=10 /$ group).

a,b Values with no common superscript differ significantly $(\mathrm{P}<0.05)$.

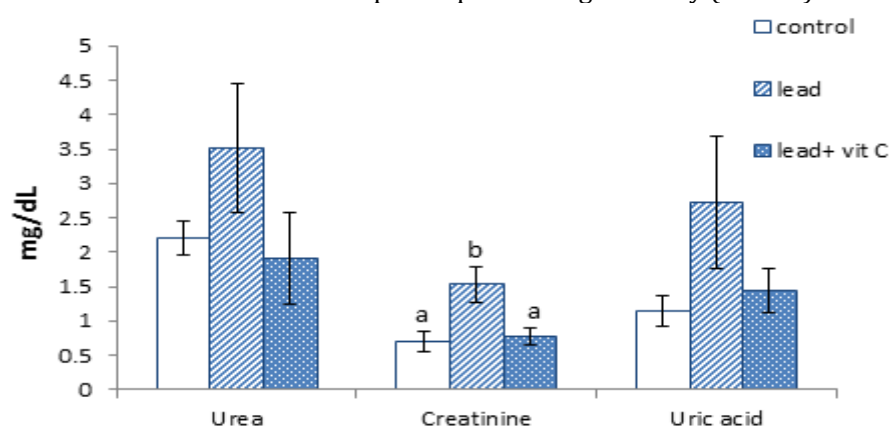

Figure 5. Plasma levels of urea, creatinine and uric acid $(\mathrm{mg} / \mathrm{dL})$ in experimental groups. Data are mean \pm SEM ( $n=10$ /group). ${ }^{a}$, b Values with no common superscript differ significantly $(\mathrm{P}<0.05)$.

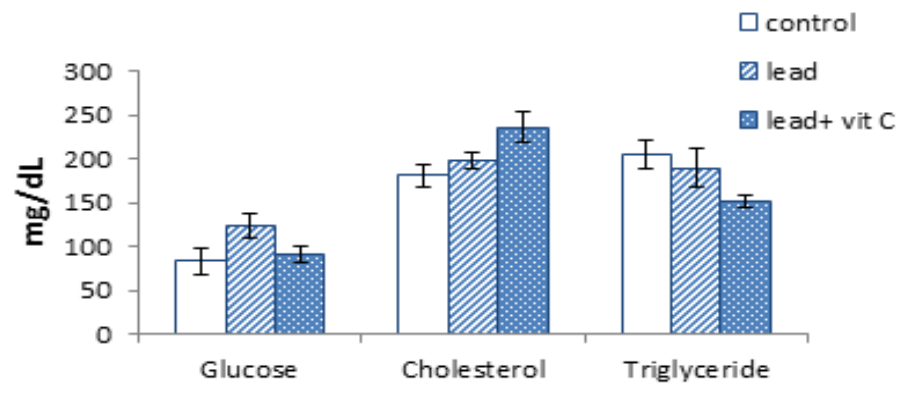

Figure 6. Plasma levels of glucose, cholesterol and triglyceride $(\mathrm{mg} / \mathrm{dL})$ in experimental groups.

Data are mean \pm SEM ( $\mathrm{n}=10 /$ group).

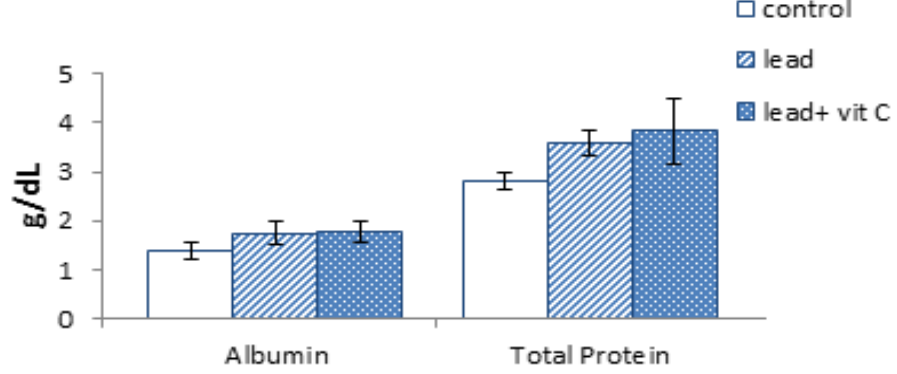

Figure 7: Plasma levels of albumin and total protein $(\mathrm{g} / \mathrm{dL})$ in experimental groups.

Data are mean \pm SEM (n=10/group).

\section{DISCUSSION}

Since the development of various industries, heavy metals have drastically polluted our environment and aquatic ecosystems. A major example is lead, which accumulates in fish and can cause serious health problems in human consumers (프). The pathogenicity of lead poisoning is primarily due to the production of ROS, causing oxidative stress on cells ( $\underline{4})$. Considering that fish is a rich source of amino acids, omega 3 fatty acids, minerals and vitamins, and is consumed widely by people, there exists a growing concern about its safety to our health. In this context, taking natural antioxidants, such as vitamin $\mathrm{C}$ when we consume fish can help us fight against free radicals. Also, this is an appropriate approach to diminish or even eliminate the adverse effects of ROS on human cells and organs (르).

A study has reported that vitamin C may have the ability to chelate lead ions $(\underline{11})$. However, another study reported a negative relationship between blood vitamin C levels and lead concentration (트). Our results suggest that vitamin $\mathrm{C}$ supplementation may not lead to a significant reduction in the blood lead levels of the exposed carp fish, in agreement with similar findings reported by Patra et al ( $\underline{13})$. These authors indicated that vitamin $\mathrm{C}$ treatment was not effective in reducing the lead levels significantly in the blood and other tissues in rats $(\underline{13})$. On the other hand, Flora and Tandon (14) found that the coadministration of vitamin $\mathrm{C}$ and thiamine was an effective approach in reducing lead levels in tissues and restoring the adverse biochemical alterations. Further, vitamin $\mathrm{C}$ has also been shown to be beneficial in restoring hematological abnormalities induced by

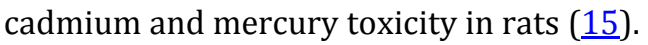


One study has suggested that lead can penetrate into fish by infiltration through gills, skin and the digestive tract $(\underline{16})$. This heavy metal can initiate oxidative stress on cells as a consequence of imbalance between antioxidants level and the generation of free radicals. Lack or low levels of antioxidants leads to cell damages mediated by free radicals in human internal systems. Moreover, since lipid molecules tend to lose electrons to free radicals, lipid peroxidation (LP) and structural and irreversible damages to proteins, DNA, cell membranes and lipids constituents of the cells occur (17). Considering the rich contents of polyunsaturated fatty acids in fish, they are very sensitive to lipid peroxidation, caused by exposure to toxic heavy metal (18). The significant rise in the plasma MDA concentration of lead-exposed C. carpio, as found in this study, is consistent with that reported in other species (19-22). Moreover, the increase in plasma MDA concentration has previously been reported in

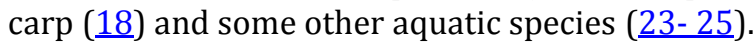

Based on the findings of this study, vitamin $C$ decreased the plasma MDA levels of lead-exposed carp to those of the control group. Consistent with our findings, Pande et al (2001) have previously shown that lead-induced lipid peroxidation was reduced significantly following treatment with antioxidants. The findings of these authors (21) also revealed that lead-provoked lipid peroxidation can be prevented significantly using dietary vitamin C. Additionally, treatment with vitamin $E$ has been effective in reducing the ROS levels and LP in rats (26) and rabbits (27) following cadmium toxicity. Similarly, vitamin E administration considerably decreased lipid peroxide levels in brain and liver of rats poisoned with lead $(\underline{13})$.

Field and laboratory experiments have demonstrated that enzymatic responses in animals, including freshwater fish, were manifested as a result of being treated with various toxins, especially heavy metals. The adverse effects were; however, dependent upon the dose, species, duration, chemical type and route of exposure to heavy metals (르). Lead-provoked adverse effects in tissues have been well established and the dysfunctions are reflected by the biochemical indices in the blood (4). The activities of certain serum enzymes have been used to diagnose health problems in fish caused by aquatic contaminants (으). Our present results demonstrated that significant increases in the plasma ALT levels occurred in the fish following exposure to lead. Fluctuations in the circulating aminotransferase levels in C. carpio have been reported previously as a result of altered metabolism following exposure to chromium ( $\underline{30})$, copper ( $\underline{31})$ and gallium (32). In addition, a significant rise in serum ALT and AST levels has been documented following cypermethrin and lead toxicities in 0. niloticus (29). Also, a significant increase in the plasma ALT found in this study might reveal the toxic effect of lead on the liver of C. carpio. Liver, which has an important role in detoxification of many xenobiotics and toxins, is one of the target organs affected by heavy metals ( $\underline{33})$.
It has been suggested that the serum uric acid, urea and creatinine may reflect renal health in the case of leadassociated renal damages $(\underline{34}, 35)$. In this context, increases in the levels of plasma creatinine, uric acid and urea that we found in C. carpio after lead exposure, might account for the nephrotoxic effects of this heavy metal.

Lastly, alterations in plasma total protein, albumin, cholesterol, triglyceride and glucose in experimental groups were not significant. In another study (모), a significant rise in cholesterol and decline of total protein after 21 days of exposure to lead has been reported in 0 . niloticus, although no significant alterations in total serum protein and cholesterol levels were documented during the initial four days (29). In this study, the plasma ALT and creatinine levels showed significant decline following treatment with vitamin $C$, suggesting the efficacy of this nutrient to prevent tissue damages caused by lead exposure.

\section{CONCLUSION}

In conclusion, lead exposure in C. carpio results in the alteration of certain plasma indices, confirming the toxic nature of this heavy metal. Moreover, vitamin $\mathrm{C}$ was shown to offer preventive potency against cellular damages caused by lead exposure in C. carpio. Thus, we conclude that the administering vitamin $\mathrm{C}$ is a safe therapeutic approach for the reduction or likely prevention of the adverse effects of lead toxicity. However, elucidation of the precise preventive mechanisms of this vitamin against lead-induced toxicity warrants further investigations.

\section{ACKNOWLEDGEMENTS}

This work was supported by a grant from Ferdowsi University of Mashhad, Mashhad, Iran.

\section{CONFLICT OF INTERESTS}

There was no conflict of interest in conducting this study.

\section{REFERENCES}

1. Tasleem Jan A,Azam M, Siddiqui K, Ali A, Choi I, Mohd Rizwanul Haq Q. Heavy metals and human health: Mechanistic insight into toxicity and counter defense system of antioxidants. Int J Mol Sci. 2015;16:2959229630.

2. Tanekhy M. Lead poisoning in Nile tilapia (Oreochromis niloticus): oxidant and antioxidant relationship. Environ Monit Assess. 2015;187(4):154.

3. Ibrahim D, Ibrahim AS, Paul ED, Umar M, Zannah UAS. Determination of some heavy metal content in tilapia and cat fish species in lake Njuwa, Adamawa state, Nigeria. J Appl Sci Environ Manage. 2018;22(8):1159 1165.

4. Patrick L. Lead txicity part II: The role of free radical damage and the use of antioxidants in the pathology and treatment of lead toxicity. Altern Med Rev. 2006; 11(2):114-127. 
5. Dawson EB, Evans DR, Harris WA, Teter MC, McGanity WJ. The effect of ascorbic acid supplementation on the blood lead levels of smokers. J Am Coll Nutr. 1999;18(2):166170.

6. Kalia K, Flora SJ. Strategies for safe and effective therapeutic measures for chronic arsenic and lead poisoning. J Occup Health. 2005;47: 1-27.

7. Wang C, Zhng Y, Liang J, Shan G, Wang Y, Shi Q. Impacts of ascorbic acid and thiamine supplementation at different concentrations on lead toxicity in testis. Clin Chim Acta. 2006;370:82-88.

8. Shahsavani D, Baghshani H, Alishahi E. Efficacy of allicin in decreasing lead $(\mathrm{Pb})$ accumulation in selected tissues of lead-exposed common carp (Cyprinus carpio). Biol Trace Elem Res. 2011;142: 572-580.

9. Todorova I, Simeonova G., Kyuchukova D, Dinev D, Gadjeva V. Reference values of oxidative stress parameters (MDA, SOD, CAT) in dogs and cats. Comp Clin Pathol. 2005;13(4):190-194.

10. Latha M, Pari L. Preventive effects of Cassia auriculata L. flowers on brain lipid peroxidation in rats treated with streptozotocin. Mol Cel Biochem. 2003; 243: 23-28.

11. Flora SJ, Mittal M, Mehta A. Heavy metal induced oxidative stress and its possible reversal by chelation therapy. Indian J Med Res. 2008; 128:501-523.

12. Simon JA, Hudes ES. Relationships of ascorbic acid to blood lead levels. JAMA. 1999; 281:2289-2293.

13. Patra RC, Swarup D, Dwivedi SK. Antioxidant effects of atocopherol, ascorbic acid and L-methionine on lead induced oxidative stress to the liver, kidney and brain in rats. Toxicol. 2001; 162:81-88.

14. Flora SJ, Tandon SK. Preventive and therapeutic effects of thiamine, ascorbic acid and their combination in lead intoxication. Acta Pharmacol Toxicol. 1986;58(5):374378.

15. Hounkpatin ASY, Johnson RC, Guédénon P, Domingo E, Alimba CG, Boko M, et al. Protective effects of vitamin C on haematological parameters in intoxicated Wistar rats with cadmium, mercury and combined cadmium and mercury. Int Res J Biolgical Sci. 2012;1(8):76-81.

16. Łuszczek-Trojnar E, Drag-Kozak E, Popek W. Lead accumulation and elimination in tissues of Prussian carp, Carassius gibelio (Bloch, 1782), after long-term dietary exposure, and depuration periods. Environ Sci Pollut Res. 2013;20: 3122-3132.

17. Matta G, Gjyli L. Mercury, lead and arsenic: impact on environment and human health. J Chem Pharm Sci. 2016;9(2):718-725.

18. Shahsavani D, Baghshani H, Aslani MR, Sadat Fatemi F. The impact of allicin on lead-induced oxidative damage in selected organs of the common carp (Cyprinus carpio). Comp Clin Pathol. 2012;21:769-775.

19. Pande M, Mehta A., Pant BP, Flora SJS. Combined administration of a chelating agent and an antioxidant in the prevention and treatment of acute lead intoxication in rats. Environ Toxicol Pharmacol. 2001; 9:173-184.

20. Aykin-Burns N, Laegeler A, Kellogg G, Ercal N. Oxidative effects of lead in young and adult Fisher 344 rats. Arch Environ Contam Toxicol. 2003; 44:417-420.
21. Flora SJ, Pande M., Mehta A. Beneficial effect of combined administration of some naturally occurring antioxidants (vitamins) and thiol chelators in the treatment of chronic lead intoxication. Chem Biol Interact. 2003;145:267-280.

22. Masso-Gonzalez EL, Antonio-Garcia MT. Natural antioxidants protect against lead-induced damage during pregnancy and lactation in rat's pups. Ecotoxicol Environ Safety. 2009;72: 2137-2142.

23. Metwally MAA, Fouad IM. Biochemical changes induced by heavy metal pollution in marine fishes at Khomse coast, Libya. Global Veterinaria. 2008;2(6):308-311.

24. Metwally MAA. Effect of garlic (Allium sativum) on some heavy metal (copper and zinc) induced alteration in serum lipid profile of Oreochromis niloticus. World J Fish Marine Sci. 2009;1(1):1-6.

25. Doherty VF, Ogunkuade 00, KanifeUC. Biomarkers of oxidative stress and heavy metal levels as indicators of environmental pollution in some selected fishes in Lagos, Nigeria. American-Eurasian J Agric and Environ Sci. 2010; 7(3):359-365.

26. Ognjanovic BI, Pavlovic SZ, Maletic SD, Zikic RV, Stajn AS, Radojicic RM, et al. Protective influence of vitamin E on antioxidant defense system in the blood of rats treated with cadmium. Physiol Res. 2003;52: 563-570.

27. Beytut E, Yuce A, Kamiloglu NN, Aksakal M.Role of dietary vitamin $\mathrm{E}$ in cadmium-induced oxidative damage in rabbit's blood, liver and kidneys. Int J Vitam Nutr Res. 2003;73: 351-355.

28. Abedi Z, Khalesi MK, Kohestan Eskandari S. Biochemical and hematological profiles of common carp (Cyprinus carpio) under sublethal effects of trivalent chromium. Iran J Toxicol. 2013;7(20):782-792.

29. Firat O, CogunHY, Yüzereroglu TA, Gok G, Firat O, Kargin $\mathrm{F}$, et al. A comparative study on the effects of a pesticide (cypermethrin) and two metals (copper, lead) to serum biochemistry of Nile tilapia, Oreochromis niloticus. Fish Physiol Biochem. 2011;37:657-666.

30. Parvathi K, Sivakumar P, Ramesh M, Sarasu. Sublethal effects of chromium on some biochemical profiles of the fresh water teleost,Cyprinuscarpio. Int J Appl Biol Pharm technol. 2011; 2(1):295-300.

31. Karan V, Vitorovic S, Tutundzic V, Poleksic V. Functional enzymes activity and gill histology of carp after copper sulfate exposure and recovery.Ecotoxol Environ Safety. 1998;40:49-55.

32. Yang JL, Chen HC. Serum metabolic enzyme activities and hepatocyte ultrastructure of common Carp after gallium exposure. Zool Stud. 2003;42(3): 455-461.

33. Vutukuru SS, Prabhath NA, Raghavender M, Yerramilli A. Effect of arsenic and chromium on the serum aminotransferases activity in Indian major carp, Labeo rohita. Int J Environ Res Public Health. 2007;4(3):224-227.

34. Anetor JI. Serum uric acid and standardized urinary protein: reliable bioindicators of lead nephropathy in Nigerian lead workers. Afr J Biomedl Res. 2002;5:19-24.

35. Memon F, Vasandani AGM., Seehar GM, Bhanger MI. Effect of low blood lead levels on anaemia indicators and creatinine clearance rate of workers occupationally exposed to lead. Pak J Physiol. 2009;5(2):31-33. 